\title{
Long-term outcome of modified maze procedure combined with mitral valve surgery: Analysis of outcomes according to type of mitral valve surgery
}

Joon Bum Kim, MD, Tae Jin Yun, MD, Cheol Hyun Chung, MD, Suk Jung Choo, MD, Hyun Song, MD, and Jae Won Lee, MD

Objective: Efficacy of the maze procedure for atrial fibrillation associated with advanced mitral disease not amenable to repair has not been determined. This study investigated whether type of mitral surgery affects maze outcome.

Methods: From January 1999 to January 2007, a total of 435 patients underwent the maze procedure and concomitant mitral operation. Of these, 226 underwent mitral repair and 209 underwent mitral replacement.

Results: Median follow-up was 40.6 months (0.4-111.3 months), with 25 deaths and 6 strokes. Nineteen patients did not regain normal sinus rhythm. There were no significant intergroup differences in survival, stroke incidence, or sinus rhythm restoration rate. Among 427 early survivors, 64 had late atrial fibrillation recurrence. Five-year atrial fibrillation-free rates were $80.9 \% \pm 3.7 \%$ in the repair group and $77.3 \% \pm 4.1 \%$ in the replacement group $(P=.099)$. By multivariate analysis, age at surgery older than 60 years $(P=.045)$, fine atrial fibrillation wave pattern $(P=.033)$, and preoperative left atrial dimension greater than $60 \mathrm{~mm}(P=.019)$ were independent risk factors for atrial fibrillation recurrence, whereas type of mitral surgery was not $(P=.573)$. Although transmitral A-wave prevalence did not differ significantly between groups beyond the early postoperative period, A-wave velocity was faster in the repair group through the entire postoperative period $(P<.001)$.

Conclusions: Maze outcomes were acceptable regardless of type of mitral surgery. Late atrial fibrillation recurrence was mainly affected by age, unfavorable electrocardiographic characteristics of atrial fibrillation, and larger preoperative left atrial size. (J Thorac Cardiovasc Surg 2010;139:111-7)

Atrial fibrillation (AF) is observed in $40 \%$ to $60 \%$ of patients who require mitral valve (MV) surgery, with the treatment of choice being the maze operation in association with MV repair when repair is technically feasible. ${ }^{1,2}$ The efficacy of the maze operation in patients who require MV replacement, however, is still unclear, ${ }^{3,4}$ in that (1) anticoagulation after valve replacement may be sufficient to prevent cerebrovascular accidents (CVAs), even without the restoration of normal sinus rhythm, and (2) the outcome of the maze operation may be less than optimal in patients with advanced MV pathology that is not reparable. Because MV replacement is indicated only for patients with difficult to correct, advanced MV pathology, such as rheumatic mitral disease, such patients probably have more advanced left atrial (LA) pathology that is arrhythmogenic, suggesting

\footnotetext{
From the Department of Thoracic and Cardiovascular Surgery, Asan Medical Center, University of Ulsan College of Medicine, Seoul, South Korea.

Received for publication Dec 28, 2008; revisions received June 2, 2009; accepted for publication July 6, 2009; available ahead of print Sept 10, 2009.

Address for reprints: Jae Won Lee, MD, Department of Thoracic and Cardiovascular Surgery, Asan Medical Center, University of Ulsan College of Medicine, 388-1

Pungnap-dong Songpa-gu, Seoul 138-736, South Korea (E-mail: jwlee@amc. seoul.kr).

$0022-5223 / \$ 36.00$

Copyright (C) 2010 by The American Association for Thoracic Surgery

doi:10.1016/j.jtcvs.2009.07.002
}

that these patients may respond poorly to efforts to eliminate AF. ${ }^{5}$

In a study evaluating the outcomes of the maze procedure combined with a MV operation, ${ }^{6} \mathrm{MV}$ replacement (rather than repair) was found to be a significant risk factor for operative mortality. That study, however, focused mainly on immediate postoperative outcomes and did not consider long-term cardiac rhythm and thromboembolic complications.

Because recurrence of AF after the maze procedure may not be directly related to the MV procedure per se, it may be important to delineate which patients can benefit from the maze operation even if the MV is to be replaced. We therefore investigated clinical results of the maze procedure combined with a MV procedure and analyzed whether the type of MV operation chosen might affect the outcome of the maze operation.

\section{MATERIALS AND METHODS \\ Patients}

From January 1999 to January 2007, a total of 435 patients with MV disease underwent surgery for persistent or paroxysmal AF. The maze procedure and the MV operation were performed concomitantly, with or without other cardiac procedures. Of these 435 patients, 226 underwent MV repair (repair group) and 209 underwent MV replacement (replacement group), depending on the severity of valve pathology. Preoperative transesophageal echocardiography was routinely performed to evaluate MV 


$$
\begin{aligned}
& \text { Abbreviations and Acronyms } \\
& \mathrm{AF}=\text { atrial fibrillation } \\
& \mathrm{CVA}=\text { cerebrovascular accident } \\
& \mathrm{LA}=\text { left atrial } \\
& \mathrm{MV}=\text { mitral valve }
\end{aligned}
$$

morphology. Rheumatic etiology of mitral valvulopathy was suggested by medical history, echocardiographic assessment, and intra-operative findings of valve morphology. In an effort to prevent postoperative sick sinus syndrome, preoperative coronary angiography was routinely performed in all patients to verify the origin and course of the sinus nodal artery. Sinus nodal arteries originated from the right coronary system in 205 patients and from the left coronary system in 152 patients. During creation of maze lesions (either incisions or ablation), these arteries were strictly preserved. This study was approved by the institutional review board.

\section{Surgical Techniques}

Maze procedures were performed with a modified Cox maze III technique, the details of which have been described previously. ${ }^{7}$ In brief, the technical modification centers around preservation of the LA function after maze operation: (1) LA tissue incorporation on pulmonary vein isolation procedure was minimized by tightly encircling the pulmonary vein orifices, (2) cut and sew technique was replaced with ablation with either cryothermia $(n=333)$ or microwave $(n=102)$, and (3) LA size was reduced by generous resection of redundant atrial tissue off the posterior LA wall parallel to the posterior mitral annulus. Cryoablation was applied at $-60^{\circ} \mathrm{C}$ with a $15^{\circ}$ angled, 30- or 70-mm long freeze tip with a diameter of $9 \mathrm{~mm}$ (Frigitronics Cardiac Cryosurgical System 200; Frigitronics, Inc, Coopersurgical, Shelton, Conn). The probe was usually applied for 2 minutes. Microwave energy was applied endocardially with FLEX 4 microwave ablation probes (Afx Inc, Fremont, Calif). The energy level used was $65 \mathrm{~W}$, and duration of ablation was 1 to 2 minutes, depending on the myocardial thickness. The degree of LA wall resection was determined by preoperative LA size, with a target postoperative LA size greater than $50 \mathrm{~mm}$. Ablation of the right atrial cavotricuspid isthmus was performed to prevent postoperative atrial flutter. MV replacement was performed in a chordae-sparing manner. One hundred seventy-five patients in the replacement group $(83.7 \%)$ received mechanical valves.

\section{Postoperative Follow-up}

Any symptoms suggestive of neurologic deficit were evaluated by neurologists with adequate imaging studies. Bleeding complication from anticoagulation therapy was defined as any significant bleeding necessitating transfusion, intervention, or readmission.

Postoperatively, inpatient rhythms were monitored daily with standard 12-channel surface electrocardiography. Patients were routinely evaluated with 24-hour Holter monitoring before hospital discharge. Follow-up electrocardiography was routinely performed at 3- to 6-month intervals during the first 2 years and every year thereafter. Any symptoms suggestive of arrhythmia were assessed by 24-hour Holter monitoring during follow-up. Recurrences or events of AF during the initial postablation blanking period of 3 months were considered early events. A failure of the maze procedure was defined as any recurrent $\mathrm{AF}$, atrial tachycardia, or atrial flutter at least 3 months after stopping amiodarone beyond the initial blanking period. The end point used was freedom from $\mathrm{AF}$ without antiarrhythmic agent, the time before first $\mathrm{AF}$ events were presented.

Transthoracic echocardiographic evaluations were performed at 3 and 6 months and every year thereafter. Two-dimensional echocardiography and Doppler color flow imaging were performed in all cases with a HewlettPackard Sonos 2500 or 5500 imaging system equipped with a $2.5-\mathrm{MHz}$ transducer (Hewlett-Packard, Andover, Mass). Patients were monitored for the presence of transmitral A waves and the magnitude of peak Awave velocity. The prevalence of transmitral A-wave as a percentage is derived from the number of patients with the presence of transmitral A wave divided by the number of patients with normal sinus rhythm multiplied by $100 \%$ at each postoperative time point.

All data were collected prospectively and stored for later assessment in a specially designed and controlled database.

\section{Postoperative Management}

Postoperative AF, atrial flutter, atrial tachycardia, frequent atrial premature beats, and recurrent atrial tachyarrhythmia were treated with amiodarone, which was commenced at $1200 \mathrm{mg} / \mathrm{d}$ and tapered according to rhythm status. Rapid ventricular rate despite amiodarone therapy was controlled by $\beta$-blockers or calcium-channel blockers. Patients who underwent valve repair or bioprosthesis insertion $(n=34)$ routinely had anticoagulation with warfarin for 3 to 6 months postoperatively with target international normalized ratio of 1.5 to 2.5 at the discretion of the attending surgeon. The maintenance of anticoagulation therapy thereafter was determined according to individual risk factors of thromboembolism and cardiac rhythm status. Any patient who showed AF after operation received anticoagulation therapy, which was continued unless sinus rhythm was restored. For patients with mechanical valve implantation, an international normalized ratio of 2.0 to 3.0 was the aim, regardless of cardiac rhythm status.

\section{Statistics}

Data are presented as frequency, mean $\pm \mathrm{SD}$, or median with range. Comparisons of patient characteristics between the groups (replacement vs repair) were performed with $\chi^{2}$ tests for categoric variables and Student $t$ tests for continuous variables. Kaplan-Meier curves were used to delineate time-related recurrence of AF. Stratified survival curves (freedom from AF) were plotted to explore unadjusted differences for variables of interest (log-rank test). For multivariate analysis, Cox proportional hazards model was fitted with time to AF recurrence, adjusting for potential risk factors. For the intergroup comparisons of transmitral A-wave prevalence and velocity at each postoperative time point, $\chi^{2}$ and Student $t$ tests, respectively, were used. Postoperative changes in transmitral peak A-wave velocity were investigated with repeated measures analysis of variance. The SPSS software package (version 12; SPSS, Inc, Chicago, Ill) was used for statistical analysis.

\section{RESULTS \\ Perioperative Characteristics}

Clinical follow-up was complete for all patients at a median of 40.6 months (0.4-111.3 months). Cardiac rhythm follow-up for 12 months was possible in 400 patients $(91.9 \%)$. Median age at operation was 52 years (18-80 years), and 264 patients $(60.6 \%)$ were female. There were no significant between-group differences in mean age at surgery, sex distribution, LA size, left ventricular ejection fraction, and cardiothoracic ratio (Table 1). Reoperation, concomitant aortic valve procedure, longer history of $\mathrm{AF}$, and rheumatic origin of mitral valvulopathy were more frequently observed in the replacement group than in the repair group.

\section{Operative Outcomes}

There were 8 early and 17 late deaths (Table 2). Nineteen patients $(4.3 \%)$ did not regain normal sinus rhythm. LA size decreased from $60.2 \pm 10.0 \mathrm{~mm}$ to $47.7 \pm 7.1 \mathrm{~mm}$ as a result of the surgery $(P<.001)$. One hundred six patients had early 
TABLE 1. Preoperative patient characteristics

\begin{tabular}{|c|c|c|c|}
\hline & Repair & Replacement & $P$ value \\
\hline Patients (No.) & 226 & 209 & \\
\hline $\operatorname{Age}(y$, mean $\pm S D)$ & $50.3 \pm 13.8$ & $51.1 \pm 11.5$ & .529 \\
\hline Male/female ratio & $97: 129$ & $74: 135$ & .109 \\
\hline $\begin{array}{l}\text { Cardiothoracic ratio }(\%, \\
\text { mean } \pm \mathrm{SD})\end{array}$ & $59.8 \pm 8.2$ & $59.3 \pm 10.3$ & .554 \\
\hline Reoperation & $8(4.4 \%)$ & $18(8.6 \%)$ & .026 \\
\hline \multicolumn{4}{|l|}{ Atrial fibrillation profile } \\
\hline Duration $(\mathrm{y}$, mean $\pm \mathrm{SD})$ & $4.5 \pm 5.0$ & $6.8 \pm 7.5$ & $<.001$ \\
\hline Coarse/fine ratio & $122: 100$ & $115: 88$ & .725 \\
\hline Type (No.) & & & .345 \\
\hline Paroxysmal & $28(12.4 \%)$ & $17(8.1 \%)$ & \\
\hline Persistent & $60(26.5 \%)$ & $59(28.2 \%)$ & \\
\hline $\begin{array}{l}\text { Longstanding persistent } \\
\qquad(>1 \mathrm{y})\end{array}$ & $138(61.1 \%)$ & $133(63.6 \%)$ & \\
\hline \multicolumn{4}{|l|}{ Echocardiography } \\
\hline $\begin{array}{l}\text { Left atrial dimension }(\mathrm{mm}, \\
\text { mean } \pm \mathrm{SD})\end{array}$ & $60.1 \pm 10.4$ & $60.2 \pm 9.5$ & .949 \\
\hline Rheumatic mitral disease & $102(45.1 \%)$ & $182(87.1 \%)$ & $<.001$ \\
\hline $\begin{array}{l}\text { Left ventricular ejection } \\
\quad \text { fraction }(\% \text {, mean } \pm \mathrm{SD})\end{array}$ & $55.2 \pm 10.7$ & $55.0 \pm 8.8$ & .806 \\
\hline
\end{tabular}

AF events (51 in the repair group and 55 in the replacement group, $P=.399)$. Of 427 early survivors, 64 had late AF recurrence $(15.0 \%)$. Normal sinus rhythm was present at last follow-up in $82.7 \%$ of patients. The overall AF-free rates were $86.2 \% \pm 1.9 \%$ at 3 years, $78.3 \% \pm 2.8 \%$ at 5 years, and $70.2 \% \pm 4.4 \%$ at 7 years. There were 6 late CVAs (no early CVAs), with 1 death and 5 permanent neurologic impairments (Table 3 ). All 6 patients with CVA were receiving anticoagulation therapy when CVA occurred. Only 1 patient in the repair group was in AF when CVA occurred; the remaining 5 were in normal sinus rhythm.

There were no significant between-group differences in CVA incidence, mortality, and rates of permanent pacemaker implantation (Table 3). There were no intergroup differences in sinus conversion rate, mean date of sinus conversion, and the last follow-up electrocardiographic rhythm (Table 4). The 5-year freedoms from AF without antiarrhythmic agent were $80.9 \% \pm 3.7 \%$ in the repair group

\section{TABLE 2. Details of mortality}

\begin{tabular}{lccc}
\hline & Repair & Replacement & $P$ value \\
\hline Early mortality $(\mathrm{n}=8)$ & 4 & 4 & \\
$\quad$ Cardiac death & 4 & 2 & $>.999$ \\
Gastrointestinal bleeding & & 1 & \\
Left ventricular rupture & & 1 & \\
Late mortality (n = 17) & 10 & 7 & .563 \\
Cardiac death & 4 & 2 & \\
Malignancy & & 2 & \\
Respiratory failure & 2 & & \\
Bacterial meningitis & 1 & & \\
Cerebrovascular accident & & 1 & \\
Unknown & 3 & 2 & \\
\hline
\end{tabular}

TABLE 3. Operative profiles and outcomes

\begin{tabular}{|c|c|c|c|}
\hline & Repair & Replacement & $P$ value \\
\hline \multicolumn{4}{|l|}{ Operative profile } \\
\hline $\begin{array}{l}\text { Aortic crossclamp time (min, } \\
\text { mean } \pm \mathrm{SD})\end{array}$ & $59.8 \pm 8.2$ & $59.3 \pm 10.3$ & .309 \\
\hline $\begin{array}{l}\text { Cardiopulmonary bypass time } \\
\quad(\text { min, mean } \pm \mathrm{SD})\end{array}$ & $114.7 \pm 30.2$ & $116.6 \pm 33.8$ & .542 \\
\hline Maze energy source (no.) & & & .107 \\
\hline Cryothermia & 166 & 167 & \\
\hline Microwave ablation & 60 & 42 & \\
\hline \multicolumn{4}{|l|}{ Concomitant procedures (no.) } \\
\hline AVR or AVP & 23 & 49 & $<.001$ \\
\hline $\mathrm{CABG}$ & 12 & 10 & .803 \\
\hline AVR or AVP plus CABG & 5 & 3 & .547 \\
\hline $\begin{array}{l}\text { Atrial, ventricular, or } \\
\text { atrioventricular septal } \\
\text { defect closure }\end{array}$ & 12 & 5 & .117 \\
\hline Aortic surgery & 4 & 0 & .830 \\
\hline Others & 4 & 5 & 649 \\
\hline \multicolumn{4}{|l|}{ Operative outcome } \\
\hline $\begin{array}{l}\text { Permanent pacemaker } \\
\text { insertion (no.) }\end{array}$ & $3(1.3 \%)$ & $7(3.3 \%)$ & .160 \\
\hline Early mortality (no.) & $4(1.8 \%)$ & $4(1.9 \%)$ & .911 \\
\hline Cerebrovascular accident (no.) & $3(1.3 \%)$ & $3(1.4 \%)$ & $>.999$ \\
\hline Multiple embolic & 2 & 3 & \\
\hline $\begin{array}{l}\text { Right middle cerebral } \\
\text { artery occlusion }\end{array}$ & 1 & & \\
\hline
\end{tabular}

and $77.3 \% \pm 4.1 \%$ in the replacement group $(P=.099$; Figure 1).

\section{Assessment of Risk Factors for Late AF Recurrence}

Univariate analyses to determine factors associated with late $\mathrm{AF}$ recurrence without antiarrhythmic agents revealed that older patient age, longer preoperative AF duration, fine $\mathrm{AF}$ wave pattern, and greater LA size were significant factors. The influences of rheumatic etiology of mitral valvulopathy, MV operation type and concomitant performance of coronary artery bypass grafting on $\mathrm{AF}$ recurrence were statistically marginal. Cox multivariate

TABLE 4. Postoperative cardiac rhythm

\begin{tabular}{lccc}
\hline & Repair & Replacement & $\boldsymbol{P}$ value \\
\hline Sinus conversion (no.) & $208(92.0 \%)$ & $196(93.8 \%)$ & .585 \\
Sinus conversion date & $1.2 \pm 2.5$ & $1.0 \pm 6.7$ & .394 \\
$\quad(\mathrm{~d}$, mean \pm SD) & & & \\
Recent follow up rhythm & & & .592 \\
$\quad$ (no.) & & & \\
Normal sinus rhythm & 188 & 172 & \\
Atrial fibrillation or & 31 & 25 & \\
$\quad$ flutter & & & \\
Junctional rhythm & 4 & 5 & \\
Pacemaker rhythm & 3 & 7 & \\
\hline
\end{tabular}




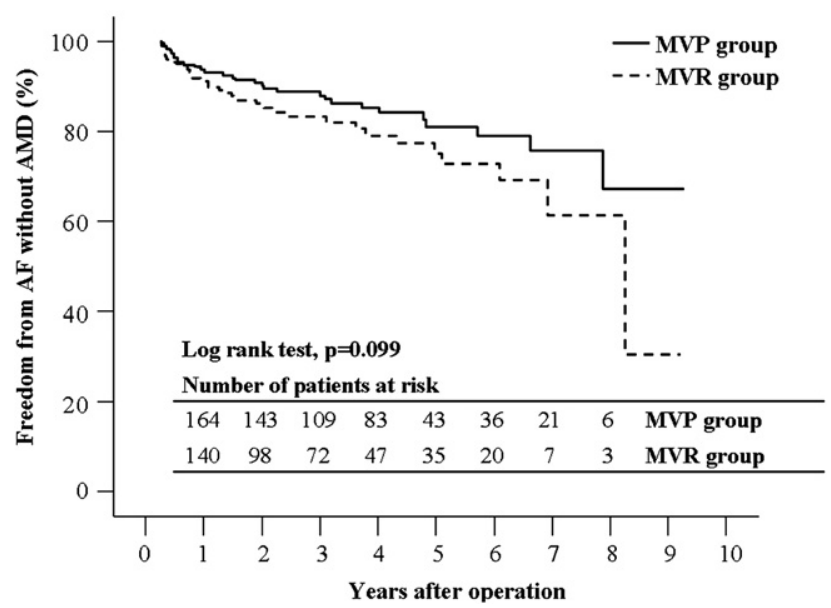

FIGURE 1. Freedoms from atrial fibrillation $(A F)$ without antiarrhythmic agents. Three- and 5-year atrial fibrillation-free rates, respectively, were $88.7 \% \pm 2.4 \%$ and $80.9 \% \pm 3.7 \%$ in repair $(M V P)$ group and $83.2 \% \pm$ $3.1 \%$ and $77.3 \% \pm 4.1 \%$ in replacement $(M V R)$ group. $A M D$, Amiodarone.

analyses including the previously mentioned variables confirmed that older patient age, fine AF wave pattern, and greater LA size were independent risk factors for late AF recurrence. After adjustment, mitral surgery type did not correlate with $\mathrm{AF}$ recurrence (Table 5).

\section{Postoperative Antiarrhythmic Medication and Anticoagulation Therapy}

Seventy-three patients in the repair group and 80 patients in the replacement group were given amiodarone within 3 months after operation $(P=.228)$. The rate of amiodarone medication in the early postoperative period ( $\leq 3$ months) was significantly greater in patients with early AF events than in those without early events $(81 / 316$ in no early events group vs 71/106 in early events group, $P<.001$ ).

Beyond 3 months after operation, 32 patients in the repair group and 27 patients in the replacement group received amiodarone medication $(P=.706)$. The rate of amiodarone medication beyond the early postoperative period $(>3$ months) was also significantly greater among patients with late $\mathrm{AF}$ recurrence than among those without late $\mathrm{AF}$ recurrence (18/317 in no AF recurrence group vs 38/64 in AF recurrence group, $P<.001)$. Three hundred seventeen patients who were free of late AF recurrence eventually had normal sinus rhythm after discontinuation of amiodarone.

After 6 postoperative months, $19.9 \%$ of patients in the repair group $(\mathrm{n}=45)$ and $91.8 \%$ in the replacement group (n $=192)$ received warfarin medication $(P<.001)$. In the repair group, the indications for long-term anticoagulation were late $\mathrm{AF}$ recurrence in 24 cases and other risk factors of thromboembolism in 21. In the replacement group, $100 \%$ of patients with mechanical valves and $50 \%$ with tissue valves $(n=17)$ received long-term anticoagulation ther-
TABLE 5. Univariate and multivariate analyses of risk factors associated with late atrial fibrillation recurrence without antiarrhythmic medication

\begin{tabular}{|c|c|c|c|c|}
\hline & \multirow[b]{2}{*}{$\begin{array}{c}\text { Univariate } \\
P \text { value }\end{array}$} & \multicolumn{3}{|c|}{ Multivariate analysis } \\
\hline & & $\begin{array}{c}\text { Hazard } \\
\text { ratio }\end{array}$ & $95 \%$ CI & $P$ value \\
\hline \multicolumn{5}{|l|}{ Preoperative factors } \\
\hline Age $(\$ 60$ y) & .023 & 1.81 & $1.01-3.22$ & .045 \\
\hline AF duration ( $\$ 5 \mathrm{y})$ & .004 & 1.45 & $0.85-2.47$ & .174 \\
\hline $\begin{array}{l}\text { Fine }(<1 \mathrm{~mm}) \text { AF wave } \\
\text { pattern (vs coarse wave) }\end{array}$ & .006 & 1.74 & $1.04-2.91$ & .033 \\
\hline \multicolumn{5}{|l|}{ AF type } \\
\hline Paroxysmal & Reference & & & \\
\hline Persistent & .453 & & & \\
\hline $\begin{array}{c}\text { Longstanding } \\
\text { persistent }\end{array}$ & .123 & & & \\
\hline Left atrial size $(\$ 60 \mathrm{~mm})$ & .009 & 1.92 & $1.11-3.33$ & .019 \\
\hline $\begin{array}{l}\text { Left ventricular ejection } \\
\text { fraction }(<50 \%)\end{array}$ & .283 & & & \\
\hline $\begin{array}{l}\text { Rheumatic mitral disease } \\
\text { (vs nonrheumatic) }\end{array}$ & .067 & 1.57 & $0.79-3.12$ & .198 \\
\hline Previous cardiac surgery & .901 & & & \\
\hline \multicolumn{5}{|l|}{ Operative factors } \\
\hline $\begin{array}{l}\text { Mitral operation type } \\
\text { (replacement vs repair) }\end{array}$ & .099 & 1.17 & $0.67-2.02$ & .573 \\
\hline $\begin{array}{l}\text { Microwave ablation (vs } \\
\text { cryoablation) }\end{array}$ & .103 & & & \\
\hline $\begin{array}{l}\text { Concomitant coronary } \\
\text { artery bypass grafting }\end{array}$ & .348 & & & \\
\hline $\begin{array}{l}\text { Concomitant aortic valve } \\
\text { surgery }\end{array}$ & .135 & 1.45 & $0.79-2.82$ & .209 \\
\hline
\end{tabular}

Not all factors were entered into the multivariate model. $C I$, Confidence interval; $A F$, atrial fibrillation.

apy. There were 34 patients who had bleeding complications during follow-up. These patients comprised $3.5 \%$ of the repair group $(\mathrm{n}=8)$ and $12.4 \%$ of the replacement group $(\mathrm{n}=$ $26, P=.001)$.

\section{Assessment for Transmitral A Waves}

In intergroup comparisons of transmitral A-wave prevalence, the only differences were found at 1 month, with higher A-wave prevalence at both time points observed in the repair group (Figure 2). Beyond the immediate postoperative period, transmitral A-wave prevalence reached $80 \%$ to $90 \%$ and was maintained for as long as 6 years.

Transmitral peak A-wave velocity was unchanged with time in both groups $(P=.146$, repeated measure analysis of variance; Figure 3). In intergroup comparisons, A-wave velocity was significantly faster in the repair group through the entire postoperative period.

\section{DISCUSSION}

We found that the outcomes of the maze procedure were comparable in the replacement and repair groups in terms of 


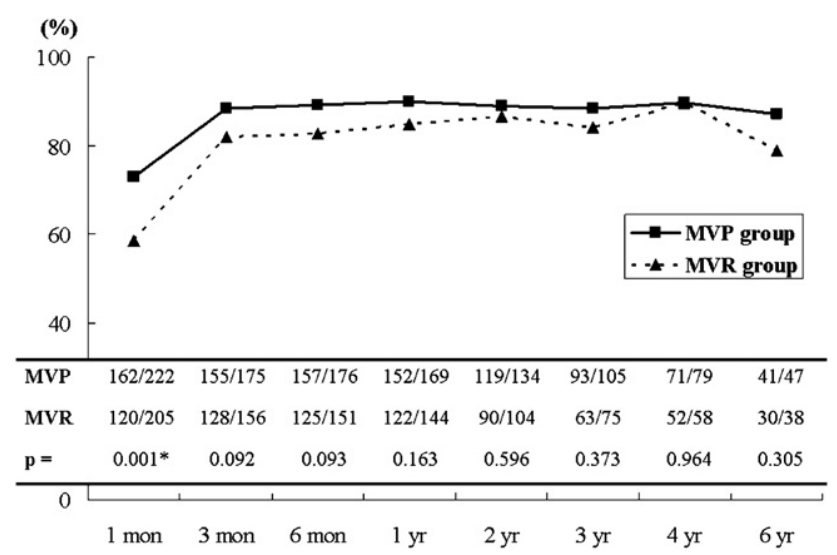

FIGURE 2. Transmitral A-wave prevalence plots. In intergroup comparisons, difference was only found at 1 month, with higher A-wave prevalence observed in repair $(M V P)$ group than in replacement $(M V R)$ group. Beyond early postoperative period, A-wave prevalence was maintained at $80 \%$ to $90 \%$ as long as 6 years without intergroup differences.

operative morbidity, overall survival, and rate of postoperative CVA. In contrast to a previously reported study, ${ }^{6}$ higher operative mortality was not observed in the replacement group. Although Kaplan-Meier analysis suggested a poorer result in the replacement group in terms of late AF recurrence with a borderline significance, multivariate analysis revealed that older patient age, fine AF wave pattern, and greater LA size were independent risk factors for postoperative AF recurrence but that the type of MV surgery was not.

To evaluate the benefits of the maze procedure in patients with MV disease, several groups have compared the outcomes of the combined procedure with those of isolated MV operation. ${ }^{4,8-11}$ A prospective trial randomly assigned 20 patients to undergo MV replacement alone $(\mathrm{n}=5)$ or in combination with a maze operation $(\mathrm{n}=15)^{8}$ and revealed that the patients who underwent the maze operation accompanied by MV replacement had much higher rate of sinus rhythm restoration and better functional performance on postoperative exercise tests. Another study compared the outcomes of patients with AF who underwent either MV replacement alone, MV repair plus the maze operation, or MV replacement plus the maze operation. ${ }^{4}$ Multivariate analyses showed that omission of the maze procedure and longer duration of $\mathrm{AF}$ were risk factors for postoperative $\mathrm{AF}$ recurrence, with omission of the maze procedure being the only significant risk factor for late stroke. Generally, the rate of major systemic embolism is $2 \%$ to $3 \%$ per year after mechanical valve replacement, even when anticoagulation treatment is used. ${ }^{12-14}$ In our study, we found that the incidence of late postoperative CVA remained low even in the replacement group, similar to that in the repair group. This finding is suggestive of an additional protective effect against CVA by restoration of sinus rhythm after the maze operation in patients with MV replacement. Similar findings

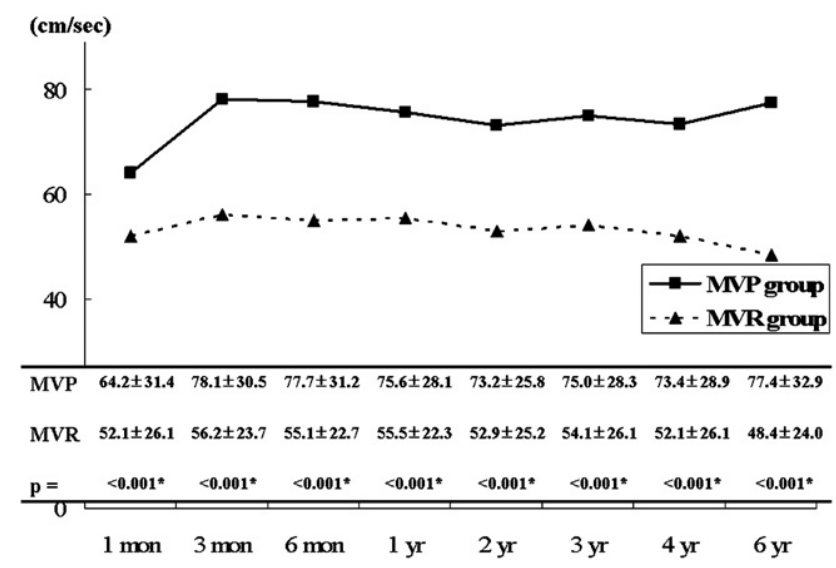

FIGURE 3. Transmitral peak A-wave velocity graphs. Repeated measures analysis of variance revealed velocity to be unchanged with time in both groups $(P=.146)$. In intergroup comparisons, A-wave velocity was significantly faster in repair $(M V P)$ group than in replacement $(M V R)$ group through entire postoperative period.

have been observed, in that CVA risk remained high in patients with MV replacement who were receiving anticoagulation and that this risk was reduced when sinus rhythm was restored. ${ }^{3,4}$ The lack of significant intergroup difference in CVA incidence might also, however, be explained by the low incidence of postoperative CVA itself $(n=6)$. Observation on a larger patient population with a longer follow-up duration might offer more complete data for more discriminating analysis of CVA incidence.

Older patient age, longer preoperative AF duration, fine AF wave pattern, and increased LA size have been shown to be risk factors for AF recurrence after the maze procedure. ${ }^{15-17}$ In our study, multivariate analyses revealed that older patient age, fine AF wave pattern, and greater LA size were independent risk factors for postoperative AF recurrence. The finding that preoperative LA size affected maze outcome is contrary to our previous report, in which patients with preoperative giant LA size $(>60 \mathrm{~mm})$ had outcomes comparable to those of patients with nongiant LA size in terms of postoperative sinus conversion rates and atrial contractility in the early and late postoperative period. ${ }^{18}$ The follow-up period of the previous study, however, was limited to only 6 postoperative months. Because this study clearly delineates an association between the LA size and AF recurrence in a long-term clinical scenario, the results from the previous report can not be generalized as a long-term maze outcome.

In this study, AF duration was not found to be an independent factor for AF recurrence. This finding may stem from the limitation in calculating the AF duration, which was based on patient memory in the case of those with symptoms (palpitation) or on the date of first recorded AF episode in the case of those without symptoms. This manner of calculation does not seem to reflect the exact duration of AF. On the other hand, the low amplitude of the AF wave indicates 
the chronic nature of AF; that is, with prolongation of AF, the atrial electric motive force decreases as a result of atrial dilatation progression, ${ }^{19}$ loss of atrial contractile components replaced with fibrosis, ${ }^{20,21}$ and degeneration of the atrial myocardium. In determining the chronic nature of $\mathrm{AF}$, evaluation the amplitude of $\mathrm{AF}$ wave is thought to be more reliable and objective than calculating $\mathrm{AF}$ duration, which mainly depends on patient memory.

The outcomes of the maze procedure have been reported to be poorer in patients with rheumatic mitral disease, suggesting that this procedure should be reconsidered in such cases. ${ }^{5}$ In contrast, another study indicated that rheumatic MV disease itself was not related to the lower success rate of the maze procedure, as assessed by sinus conversion and restoration of atrial transport function, ${ }^{22}$ findings in agreement with those shown in this study. According to our multivariate analysis, the presence of rheumatic disease did not affect $\mathrm{AF}$ recurrence after the maze operation $(P=.116)$.

Assessment of atrial transport function is regarded as an important part of the analysis of maze outcomes. The importance of atrial contractility in patients with restored sinus rhythm has been a subject of controversy, however, in that restoration of atrial transport function may not contribute to increased cardiac output or decreased thromboembolic complications. A study that involved cardiopulmonary exercise testing before and after the maze procedure suggested that improvement in exercise capacity may not be caused by restored sinus rhythm and atrial contraction but may be related to the reduction in LA size and improvement in hemodynamic variables achieved by the surgery itself. ${ }^{23}$ In a recently reported study, however, cardiac magnetic resonance imaging evaluation for patients who had sinus rhythm following maze procedure revealed that patients with atrial contraction had better LA booster pump and reservoir function than did those without atrial contraction. ${ }^{24}$ The latter report strongly suggests better cardiac performances in patients with both sinus rhythm and atrial contraction after the maze procedure. In our series, the modification of the maze procedure was intended to improve the LA transport function under the assumption that restoration of atrial transport function plays an important role in overall outcome. Furthermore, patients with sinus rhythm but without effective atrial contraction routinely received anticoagulation in our practice to prevent potential thromboembolic complications.

In this study, A-wave prevalence increased from $58 \%$ to $73 \%$ the in early postoperative period (1 month) to $80 \%$ to $90 \%$ thereafter and was maintained as late as 6 years. In intergroup comparison, the difference in A-wave prevalence was observed only at 1 postoperative month, with a higher A-wave prevalence in the repair group. Restoration of both sinus rhythm and atrial contractility is apparently different, and the rate of restoring atrial contraction varies from
$21 \%$ to $95 \%$, with factors affecting restoration of atrial contraction after the maze procedure known to be AF duration, LA diameter, and the presence of prosthetic valve failure. ${ }^{25}$ MV operation type was greatly associated with the postoperative A-wave velocity in this study, which was less favorable in the replacement group than in the repair group. This finding is thought to be attributable to the differences in preoperative conditions, which were poorer in the replacement group, with rheumatic mitral valvulopathy and reoperation more frequently observed in the replacement group than in the repair group. These adverse conditions may have resulted in degenerative changes of atrial tissue characterized by loss of atrial muscle and atrial fibrosis and thus decreased contractility of atria. Clinical implications of the differences in A-wave velocity and the effect of each factor on it should be investigated in another study.

\section{LIMITATIONS}

This study was retrospective in nature and was not randomized. We have not determined whether a successful maze procedure can reduce the risk of thromboembolism. Although we speculated that $\mathrm{AF}$ recurrence increases the risk of CVA, any correlation between these variables was not provable in this study because of the low incidence of postoperative thromboembolic complications. Data from a larger population of patients with longer follow-up duration might resolve these limitations. The clinical implications of restored atrial contraction and its relationship with MV operation type still remain unclear. This lack of clarity merits a further study analyzing the clinical significance of atrial contractility and the influences of various potential factors on atrial contractility.

\section{CONCLUSIONS}

The addition of the maze procedure to MV surgery was safe and effective in the treatment of AF associated with MV disease. The clinical outcomes of the maze procedure were excellent, regardless of type of MV surgery. Late AF recurrence was mainly affected by patient age, electrocardiographic characteristics of $\mathrm{AF}$, and larger preoperative LA size, not by type of MV surgery. Although LA contraction was restored in most patients, LA contractility remained less favorable in patients with MV replacement than in those with MV repair.

\section{References}

1. Feinberg MS, Waggoner AD, Kater KM, Cox JL, Lindsay BD, Pérez JE. Restoration of atrial function after the maze procedure for patients with atrial fibrillation. Assessment by Doppler echocardiography. Circulation. 1994;90(5 Pt 2): II285-92.

2. Khargi K, Hutten BA, Lemke B, Deneke T. Surgical treatment of atrial fibrillation; a systematic review. Eur J Cardiothorac Surg. 2005;27:258-65.

3. Bando K, Kobayashi J, Hirata M, Satoh T, Niwaya K, Tagusari O, et al. Early and late stroke after mitral valve replacement with a mechanical prosthesis: risk factor analysis of a 24-year experience. J Thorac Cardiovasc Surg. 2003;126:358-64. 
4. Bando K, Kobayashi J, Kosakai Y, Hirata M, Sasako Y, Nakatani S, et al. Impact of Cox maze procedure on outcome in patients with atrial fibrillation and mitral valve disease. J Thorac Cardiovasc Surg. 2002;124:575-83.

5. Fukada J, Morishita K, Komatsu K, Sato H, Shiiku C, Muraki S, et al. Is atrial fibrillation resulting from rheumatic mitral valve disease a proper indication for the maze procedure? Ann Thorac Surg. 1998;65:1566-70.

6. Izumoto H, Kawazoe K, Kitahara H, Kamata J. Operative results after the Cox/ maze procedure combined with a mitral valve operation. Ann Thorac Surg. 1998;66:800-4

7. Lee JW, Choo SJ, Kim KI, Song JK, Kang DH, Song JM, et al. Atrial fibrillation surgery simplified with cryoablation to improve left atrial function. Ann Thorac Surg. 2001;72:1479-83.

8. Deneke T, Khargi K, Grewe PH, Laczkovics A, von Dryander S, Lawo T, et al. Efficacy of an additional MAZE procedure using cooled-tip radiofrequency ablation in patients with chronic atrial fibrillation and mitral valve disease. A randomized, prospective trial. Eur Heart J. 2002;23:558-66

9. Handa N, Schaff HV, Morris JJ, Anderson BJ, Kopecky SL, EnriquezSarano M. Outcome of valve repair and the Cox maze procedure for mitral regurgitation and associated atrial fibrillation. J Thorac Cardiovasc Surg. 1999; 118:628-35.

10. Jatene MB, Marcial MB, Tarasoutchi F, Cardoso RA, Pomerantzeff P, Jatene AD. Influence of the maze procedure on the treatment of rheumatic atrial fibrillationevaluation of rhythm control and clinical outcome in a comparative study. Eur J Cardiothorac Surg. 2000;17:117-24

11. Raanani E, Albage A, David TE, Yau TM, Armstrong S. The efficacy of the Cox/ maze procedure combined with mitral valve surgery: a matched control study. Eur J Cardiothorac Surg. 2001;19:438-42.

12. Fiore AC, Barner HB, Swartz MT, McBride LR, Labovitz AJ, Vaca KJ, et al. Mitral valve replacement: randomized trial of St. Jude and Medtronic Hall prostheses. Ann Thorac Surg. 1998;66:707-13.

13. Hammermeister KE, Sethi GK, Henderson WG, Oprian C, Kim T, Rahimtoola S. A comparison of outcomes in men 11 years after heart-valve replacement with a mechanical valve or bioprosthesis. Veterans Affairs Cooperative Study on Valvular Heart Disease. N Engl J Med. 1993;328:1289-96.
14. Turpie AG, Gent M, Laupacis A, Latour Y, Gunstensen J, Basile F, et al. A comparison of aspirin with placebo in patients treated with warfarin after heart-valve replacement. N Engl J Med. 1993;329:524-9.

15. Gillinov AM, Sirak J, Blackstone EH, McCarthy PM, Rajeswaran J, Pettersson G, et al. The Cox maze procedure in mitral valve disease: predictors of recurrent atrial fibrillation. $J$ Thorac Cardiovasc Surg. 2005;130:1653-60.

16. Izumoto H, Kawazoe K, Eishi K, Kamata J. Medium-term results after the modified Cox/Maze procedure combined with other cardiac surgery. Eur J Cardiothorac Surg. 2000;17:25-9.

17. Kamata J, Kawazoe K, Izumoto H, Kitahara H, Shiina Y, Sato Y, et al. Predictors of sinus rhythm restoration after Cox maze procedure concomitant with other cardiac operations. Ann Thorac Surg. 1997;64:394-8.

18. Choo SJ, Park NH, Lee SK, Kim JW, Song JK, Song H, et al. Excellent results for atrial fibrillation surgery in the presence of giant left atrium and mitral valve disease. Eur J Cardiothorac Surg. 2004;26:336-41.

19. Henry WL, Morganroth J, Pearlman AS, Clark CE, Redwood DR, Itscoitz SB et al. Relation between echocardiographically determined left atrial size and atrial fibrillation. Circulation. 1976;53:273-9.

20. Bailey GW, Braniff BA, Hancock EW, Cohn KE. Relation of left atrial pathology to atrial fibrillation in mitral valvular disease. Ann Intern Med. 1968;69:13-20.

21. Davies MJ, Pomerance A. Pathology of atrial fibrillation in man. Br Heart J. 1972; 34:520-5.

22. Lee JW, Park NH, Choo SJ, Jo MS, Song H, Song MG. Surgical outcome of the maze procedure for atrial fibrillation in mitral valve disease: rheumatic versus degenerative. Ann Thorac Surg. 2003;75:57-61.

23. Yuda S, Nakatani S, Kosakai Y, Satoh T, Goto Y, Yamagishi M, et al. Mechanism of improvement in exercise capacity after the maze procedure combined with mitral valve surgery. Heart. 2004;90:64-9.

24. Marui A, Saji Y, Nishina T, Tadamura E, Kanao S, Shimamoto T, et al. Impact of left atrial volume reduction concomitant with atrial fibrillation surgery on left atrial geometry and mechanical function. J Thorac Cardiovasc Surg. 2008;135:1297-305.

25. Yuda S, Nakatani S, Kosakai Y, Yamagishi M, Miyatake K. Long-term follow-up of atrial contraction after the maze procedure in patients with mitral valve disease. J Am Coll Cardiol. 2001;37:1622-7.

\title{
COMMENTARY
}

\section{The quest to identify predictors for success and failure after the Cox-Maze procedure for the treatment of atrial fibrillation}

\author{
Niv Ad, MD
}

In this issue of the Journal, Dr Joon Bum Kim and colleagues $^{1}$ present their experience with more than 400 patients who underwent the modified Cox-Maze III procedure combined with mitral valve surgery. This is a retrospective study designed to answer the interesting question of

From the Inova Heart and Vascular Institute, Falls Church, Va.

Received for publication July 12, 2009; accepted for publication July 21, 2009.

Address for reprints: Niv Ad, MD, Inova Heart and Vascular Institute, 3300 Gallows

Rd, Falls Church, VA 22042 (E-mail: nivadmd@hotmail.com).

J Thorac Cardiovasc Surg 2010;139:117-8

$0022-5223 / \$ 36.00$

Copyright $(c) 2010$ by The American Association for Thoracic Surgery

doi:10.1016/j.jtcvs.2009.07.054 whether the type of mitral valve surgery performed has any impact on the success rate of the surgical ablation.

This is a relatively large report to include 435 patients (226 patients in the repair group). The main conclusion of this study is that the success rate in ablation atrial fibrillation was not affected by the type of the mitral valve surgery (repair or replacement); however, left atrial transport was documented to be superior in the repair group. The predictors for failure that were recognized in the study were the preoperative age, fine atrial fibrillation wave pattern, and left atrial size more than $6 \mathrm{~cm}$ preoperatively.

The authors of this article are to be congratulated for their excellent results in a large series of patients. Nevertheless, 